\title{
Differences in HIV testing and receipt of results between adolescent and non-adolescent women in Uganda
}

Stephen Ediru ${ }^{1,2^{*}} \mathbb{0}$, Robert Wamala ${ }^{3}$ and Betty Kwagala ${ }^{1}$

\begin{abstract}
Despite notable increase in HIV testing among Uganda's women from 25\% in 2006 to $71 \%$ in 2011, HIV testing among adolescent women remains very low at $45.5 \%$. This study assesses differences in HIV testing and receipt of results (HTR) between adolescent and non-adolescent women in Uganda. The differences were decomposed into components attributed to variation in characteristics and variation in effects of characteristics in the two groups. The assessment was based on data sourced from 2011 Uganda Demographic Health Survey. Statistical analysis was done using a Non-linear Oaxaca'Blinder Multivariate Decomposition of the logistic regression. In the results, the difference in HIV testing and receipt of result between adolescent and non-adolescent women was significantly $(P<0.05)$ attributed to both variation in characteristics (57.2\%) and variation in the effects of characteristics/coefficients (42.8\%). In particular, the gap in HTR was mainly attributed to variation in characteristics such as ever had sex (34.7\%) and ever given birth (31.6\%) and variation in effects of characteristics such as education level (-68.8\%) and marital status (-12.6\%). Based on the findings of the study, government and other development partners need to scale up HIV testing programs targeting adolescents through tackling stigma, increasing on community outreach services and expanding adolescent friendly HIV services center.
\end{abstract}

Keywords: HIV testing, Receipt, Result, Adolescents, Non-adolescents, Decomposition

\section{Background}

Globally, Acquired Immunodeficiency Syndrome (HIV/ AIDS) pandemic remains a major challenge to public health [19]. By the end of 2012, an estimated 35.3 million people were living with HIV worldwide [20]. Out of the 35.3 million people, 2.1 million were adolescents, with female accounting for $56 \%$ [20]. This pattern of HIV infection is not surprising considering the early adolescents' initiation into sexual activity. For instance, in Uganda, $60 \%$ of young women had initiated sexual activity by age 18 years in 2011 [17].

HIV testing and receipt of results is the gateway to HIV/AIDS prevention, treatment and care programs [19]. HIV testing has been recommended as a routine

\footnotetext{
*Correspondence: stephenediru@gmail.com

${ }^{1}$ Department of Population Studies, School of Statistics and Planning,

Makerere University, P.O BOX 7062, Kampala, Uganda

Full list of author information is available at the end of the article
}

health care service for young people [3]. However, evidence shows that $53.3 \%$ of people living with HIV globally do not know their HIV status and yet timely access to treatment and related prevention services require knowledge of one's HIV status [5]. By 2011, only about $1 / 3$ of young people knew their HIV status [11]. In sub-Saharan Africa, almost $90 \%$ of people who tested positive for HIV went on to access Antiretroviral Therapy (ART) and evidence indicates that $76 \%$ of people on ART have achieved viral suppression [6]. Research evidence has demonstrated that fear of HIV testing is associated with limited consent, little privacy and breaches of confidentiality [7]. While adolescent women generally fear test result, married women fear reactions from their husbands in case the HIV test result is positive [2].

Despite tremendous increase in HIV testing and receipt of results among Uganda's women from 25\% in 2006 to $71 \%$ in 2011, HIV testing among adolescent women has remained very low at $45.5 \%$ [16]. Research evidence 
reveals that acceptance of HIV testing among women is associated with greater number of antenatal care visits, residing in the urban areas, having comprehensive knowledge on HIV and positive partner's reaction for HIV positive result [9]. Twenty-five percent of Uganda's population is comprised of adolescents [17]. Being young and female in Africa tends to increase female adolescents' sexual risks and vulnerabilities to HIV [8]. Increasing access to and uptake of HIV testing is critical to reduce the incidence of HIV and to improve access to treatment and support for sero-positive people. People who are aware of being HIV-positive are less likely to engage in sexual risk behavior and people who receive antiretroviral treatment (ART) and adhere to it are less likely to infect others [12]. Moreover, stigma is likely to decline because as more people become aware of their sero-status, it becomes normal for them to voluntarily disclose their HIV sero-status [15].

Uganda is one of the Sub-Saharan countries with the highest HIV/AIDS prevalence (7.3\%). Women in Uganda bear the biggest burden of HIV prevalence $(8.3 \%)$ compared to men (6.1\%) [18]. Low HIV testing and receipt of results has been associated with increased risky sexual behaviors, infections and delayed access to early treatment, care and support among women [4]. Recent studies on the determinants of HIV testing among women in Sub-Saharan Africa, Uganda inclusive are routinely assessed statistically using methodologies in which age is only included as a covariate $[1,10-12,21]$. Certainly, these approaches provide insight into the relative contributions of different age groups [13]. However, these approaches are limited in terms of partitioning differences in HIV testing into a component attributed to difference in composition of women by characteristics and a component attributed to difference in behavior as a result of difference in characteristics between adolescent and non-adolescent women. In particular, the extent to which difference in HIV testing can be attributed to compositional differences between adolescent and non-adolescent women remains unanswered. Likewise, the extent to which the difference is attributed to the behavioral differences between adolescent and non-adolescent women is yet to be established.

\section{Methodology}

The study utilized data from 2011 Uganda Demographic Health Survey (UDHS). As part of the requirements, authors submitted a proposal to DHS Program/ICF International and permission was granted to download and use data for the study. DHS authorized data access, and the data was used only for the purpose of the current study. This data is from a nationally representative sample of households obtained at two- stage cluster sampling
(UBOS and ICF International, 2012). The first stage involved the selection of cluster sample; this was followed by selection of households. Stratification of urban and rural areas was taken into account. The UDHS for 2011 was based on four data collection tools but for this investigation only women's questionnaire was used. In the 2011 UDHS, women 15-49 were asked if they knew a place where they could go to be tested and further if they had ever undergone an HIV test and received the results of the test. The data was collected from ten regions of Uganda. Women were grouped adolescent aged 15-19 $(\mathrm{n}=2048)$ and non-adolescent aged 20-49 $(\mathrm{n}=6648)$. Data was weighted to ensure representativeness of the sampled data.

\section{Variables}

The dependent variable was HIV testing and receipt of results. The variable had two outcomes: tested and received result or not tested/tested but did not receive result. The independent variables include; Place of residence (urban, rural), Education level (no education, primary, post-primary), region (Kampala, Central 1, Central 2, East Central, Eastern, North, Karamoja, West-Nile, Western, Southwest), Religion (Catholics, Protestant, Muslim, Pentecostal, Other), Wealth index (Poorest, Poorer, Middle, Richer, Richest), marital status (Never in union, married, widowed/separated), ever given birth (yes, no), ever had sex (yes, no), comprehensive knowledge on HIV (have comprehensive, did not have comprehensive knowledge) and HIV stigma (have HIV stigmatizing attitudes, did not have HIV stigmatizing attitudes). HIV stigma was generated from four variables namely willingness to take care of a family member with HIV/AIDS, willingness to buy fresh vegetables from HIV positive vender; allowing a HIV positive teacher who is not sick to continue teaching and would not want to keep secret that a family member has HIV/AIDS. On the other hand, Comprehensive knowledge was generated from variables such as; knowing that consistent use of condom during sexual intercourse and having just one uninfected faithful partner can reduce chance of getting AIDS virus; rejecting misconceptions namely; AIDS can be transmitted by mosquito bite and a person can get infected by sharing food with an infected person.

\section{Statistical analysis}

Statistical analysis was undertaken using STATA 12.0 at three levels: First, a descriptive summary indicating differentials in women's characteristics was performed using frequency distribution. Secondly, difference in HIV testing and receipt of results between adolescent and non-adolescent women distributed according to their characteristics was performed using frequency 
distribution showing percentage difference. Thirdly, Multivariate decomposition model which was used to portion differences in HIV testing and receipt of result between adolescent and non-adolescent women into components attributable to variation in characteristics and variation in effects of characteristics between the two groups. All associations were deemed statistically significant at a cutoff P-value of 0.05 .

\section{Results}

This section of the paper presents results of the study including percentage distribution of women by characteristics, percentage distribution of women by HIV testing and receipt of results, differences in HIV testing and receipt of results between adolescent and non-adolescent women by characteristics and decomposition of differences in HIV testing and receipt of results.

\section{Difference in composition of women by characteristics}

The characteristics of women assessed in the study were; level of education, place of residence, region, religion, wealth index, marital status, ever given birth, ever had sex, comprehensive knowledge on HIV and HIV stigma. Table 1 presents distribution of adolescent (15-19) and non-adolescent (20-49) women by these characteristics.

From Table 1, notable difference in distribution of women by their characteristics was observed in the following variables; marital status, ever given birth, ever had sex, HIV stigma, comprehensive knowledge, wealth index and education level.

The findings in Table 1 reveal that majority of women in this study were rural residents $(80.7 \%$ of the adolescent women and $80.1 \%$ of the non-adolescent women). In terms of education attainment, more women had primary level of education across all the two groups $(64.8 \%$ of the adolescents and $57.7 \%$ of the non-adolescents). However, about $16 \%$ of non-adolescent women had no education compared to only $2.9 \%$ of the adolescent women. Findings on regional distribution indicate that in both groups, more women were from eastern region $(15.5 \%$ of the adolescent and $14.3 \%$ of the non-adolescents) and western region $(14.0 \%$ of the adolescents and $14.1 \%$ of the non-adolescents).

Results in Table 1 further show that $40.6 \%$ of women in both groups were Catholics. Similarly, most of women were in the richest $26.2 \%$ of adolescents and $25.7 \%$ of the non-adolescents) and richer wealth quintile (23.5\% adolescents and $18.8 \%$ non-adolescents). Almost all (97.6\%) non-adolescent women had ever had sex compared to only $45.1 \%$ of their adolescent counterpart. While majority of adolescents were never in union $(77.3 \%)$, more of the non-adolescents were married (75.6\%). Similarly $91.8 \%$ of the non-adolescent women had given birth
Table 1 Distribution of women by characteristics

\begin{tabular}{|c|c|c|c|}
\hline Characteristics & $\begin{array}{l}\text { Adolescents } \\
(n=2048)\end{array}$ & $\begin{array}{l}\text { Non- } \\
\text { adolescents } \\
(n=6626)\end{array}$ & Difference \\
\hline \multicolumn{4}{|l|}{ Residence } \\
\hline Urban & 19.3 & 19.9 & 0.6 \\
\hline Rural & 80.7 & 80.1 & -0.6 \\
\hline \multicolumn{4}{|l|}{ Education } \\
\hline No education & 2.9 & 16.0 & 13.1 \\
\hline Primary & 64.8 & 57.7 & -7.1 \\
\hline Post-primary & 32.3 & 26.3 & -6.0 \\
\hline \multicolumn{4}{|l|}{ Region } \\
\hline Kampala & 9.3 & 9.8 & 0.5 \\
\hline Central 1 & 11.2 & 10.9 & -0.3 \\
\hline Central 2 & 9.7 & 10.6 & 0.9 \\
\hline East central & 9.9 & 10.1 & 0.2 \\
\hline Eastern & 15.5 & 14.3 & -1.2 \\
\hline North & 8.8 & 8.4 & -0.4 \\
\hline Karamoja & 3.2 & 3.4 & 0.2 \\
\hline West-Nile & 6.2 & 5.6 & -0.6 \\
\hline Western & 14.0 & 14.1 & 0.1 \\
\hline Southwest & 12.2 & 12.8 & 0.6 \\
\hline \multicolumn{4}{|l|}{ Religion } \\
\hline Catholic & 40.6 & 40.6 & 0.0 \\
\hline Protestant & 29.2 & 30.2 & 1.0 \\
\hline Muslim & 13.4 & 12.9 & -0.5 \\
\hline Pentecostal & 13.7 & 13.2 & -0.5 \\
\hline Other & 3.1 & 3.1 & 0.0 \\
\hline \multicolumn{4}{|l|}{ Wealth index } \\
\hline Poorest & 15.4 & 18.2 & 2.8 \\
\hline Poorer & 16.9 & 18.6 & 1.7 \\
\hline Middle & 18.0 & 18.7 & 0.7 \\
\hline Richer & 23.5 & 18.8 & -4.7 \\
\hline Richest & 26.2 & 25.7 & -0.5 \\
\hline \multicolumn{4}{|l|}{ Marital status } \\
\hline Never in union & 77.3 & 8.1 & -69.2 \\
\hline Married/living together & 19.9 & 75.6 & 55.7 \\
\hline Widowed/separated & 2.8 & 16.3 & 13.5 \\
\hline \multicolumn{4}{|l|}{ Ever given birth } \\
\hline No & 81.9 & 8.2 & -73.7 \\
\hline Yes & 18.1 & 91.8 & 73.7 \\
\hline \multicolumn{4}{|c|}{ Have comprehensive knowledge } \\
\hline No & 64.4 & 61.6 & -2.8 \\
\hline Yes & 35.6 & 38.4 & 2.8 \\
\hline \multicolumn{4}{|l|}{ Ever had sex } \\
\hline No & 54.9 & 2.4 & -52.5 \\
\hline Yes & 45.1 & 97.6 & 52.5 \\
\hline \multicolumn{4}{|c|}{ Have HIV stigmatizing attitude } \\
\hline No & 80.9 & 76.8 & -4.1 \\
\hline Yes & 19.1 & 23.2 & 4.1 \\
\hline
\end{tabular}

The assessment is based on weighted data 
compared only $18.1 \%$ of the adolescent women. In both groups, more women did not have comprehensive knowledge on HIV (64.4\% of the adolescents and $61.6 \%$ of the non-adolescent women). Less stigmatizing attitude was reported in both groups $(23.2 \%$ among non-adolescents and $19.1 \%$ among adolescent women).

\section{HIV testing and receipt of results}

As earlier on noted, HIV testing and receipt of results was assessed based on binary outcome which included; tested and received results or never tested/tested and never received results.

In the results according to Fig. 1, only $45.5 \%$ of adolescent women tested and received HIV results compared to $79.3 \%$ of non-adolescent women who tested and received results. This result leaves a very big difference in HIV testing and receipt of results between adolescents and non-adolescent women in Uganda (33.8\%) implying that there was low uptake of HIV testing among female adolescents compared to non-adolescent women.

\section{Differentials in HIV testing and receipt of results}

Table 2 presents differences in HIV testing and receipt of result between adolescent and non-adolescent women distributed by their characteristics.

Results presented in Table 2 above indicate a significant relationship between residence and HIV testing and receipt of result in all the two groups $(\mathrm{P}=0.000)$. HIV testing and receipt of result was found to be high among non-adolescent women in both urban (87.3\%) and rural (77.4\%) areas compared to female adolescents. Highest level of education attained also indicated a significant association with HIV testing and receipt of result in both adolescent and non-adolescent women $(\mathrm{P}=0.00)$. In all the two groups, HIV testing and receipt of result was high among women with post-primary level of education while non HIV testing was significantly high among

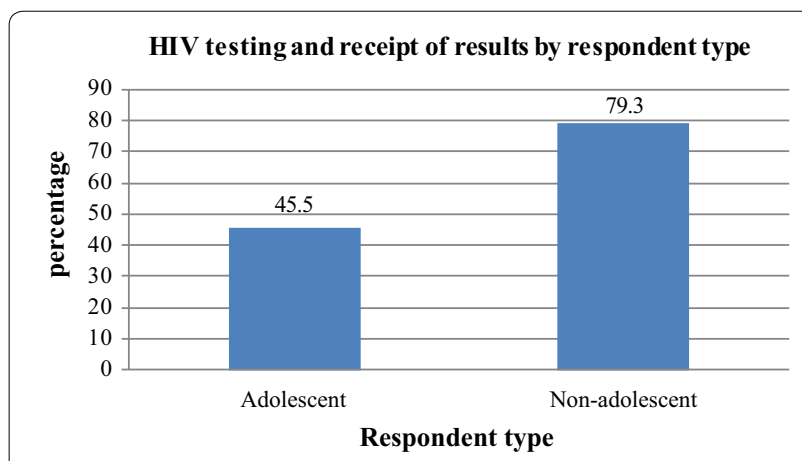

Fig. 1 Distribution of women by HIV testing behavior women with no level of education attained (73.3\% in adolescents and $32.9 \%$ in non-adolescents).

With regard to region, HIV testing and receipt of result among female adolescents was high in Kampala (49.5\%), West (48.2\%) and Central 1 (47.3\%) while among nonadolescent women HIV testing and receipt of result was high in North (88.6\%), Kampala (86.3\%) and Central 1 (81.2\%). HIV testing and receipt of result also increased for women in the richest wealth quintile $(50.3 \%$ in adolescents and $86.7 \%$ in non-adolescents). However, there was no significate relationship between HIV testing and wealth quintile among female adolescent women $(\mathrm{P}=0.137)$.

HIV testing only indicated significant association with marital status among female adolescent $(\mathrm{P}=0.000)$ and no association among non-adolescent women $(\mathrm{P}=0.134)$. In all the two groups, HIV testing was high among women who are married. Similarly, increase in HIV testing has been associated with women who have ever given birth ( $82 \%$ for adolescents and $80.1 \%$ for nonadolescents). Increase in HIV testing uptake was also found to be high among and with no stigmatizing attitudes towards people living with HIV/AIDS (57.3\% for adolescent women and $85.5 \%$ for adolescent women).

\section{Decomposition of differences in HIV testing and receipt of results}

A multivariate decomposition logistic regression model was used to decompose differences in HIV testing and receipt of results (HTR) between adolescents and nonadolescents women attributed to variation in their characteristics/endowments (E) and variation in the effects of the predictors/coefficients (C). Tables 3 and 4 present decomposition results of differences in HIV testing and receipt of results between adolescent and non- adolescent women.

According to the results in Table 3, differences in HIV Testing and Receipt of results between adolescent and non-adolescent women were significantly attributed to both differences in the characteristics and variation effects of predictors of the two groups $(\mathrm{P}<0.05)$. Overall, about $57.2 \%$ of the gap in HTR can be attributed to differences in characteristics while $42.8 \%$ of the gap in HTR can be attributed to differences in effects of predictors or coefficients between adolescent and non-adolescent women.

Overall, Variation in the characteristics of adolescent and non-adolescent women contributed about 57.2\% to the overall difference in HIV testing and receipt of results between adolescent and non-adolescent women. Specifically, the differences were significantly attributed to characteristics of women namely; education, place of residence, region, ever given birth, ever 
Table 2 Differences in HIV testing and receipt of results between adolescent and non-adolescent women

\begin{tabular}{|c|c|c|c|c|c|}
\hline \multirow[t]{2}{*}{ Characteristics } & \multicolumn{2}{|c|}{ Adolescents (2048) } & \multicolumn{2}{|c|}{ Non-adolescent (6626) } & \multirow{2}{*}{$\begin{array}{l}\text { Differences in HIV } \\
\text { testing and receipt } \\
\text { of result }\end{array}$} \\
\hline & $\begin{array}{l}\text { Tested } \\
\text { and received } \\
\text { result }\end{array}$ & $\begin{array}{l}\text { Never tested/tested } \\
\text { but never received result }\end{array}$ & $\begin{array}{l}\text { Tested } \\
\text { and received } \\
\text { result }\end{array}$ & $\begin{array}{l}\text { Never tested/tested } \\
\text { but never received result }\end{array}$ & \\
\hline Residence & $P=0.000$ & $x=18.638$ & $P=0.000$ & $x=127.923$ & \\
\hline Urban & 51.8 & 48.2 & 87.3 & 12.4 & 35.5 \\
\hline Rural & 44.0 & 56.0 & 77.4 & 22.6 & 33.4 \\
\hline Education & $P=0.000$ & $x=56.515$ & $P=0.000$ & $x=253.432$ & \\
\hline No education & 26.7 & 73.3 & 67.1 & 32.9 & 40.4 \\
\hline Primary & 42.2 & 57.8 & 79.1 & 20.9 & 36.9 \\
\hline Post-primary & 53.8 & 46.2 & 87.5 & 12.5 & 33.7 \\
\hline Region & $P=0.000$ & $x=52.961$ & $P=0.000$ & $x=249.999$ & \\
\hline Kampala & 49.5 & 50.5 & 86.3 & 13.7 & 36.8 \\
\hline Central 1 & 47.3 & 52.7 & 81.2 & 18.8 & 33.9 \\
\hline Central 2 & 44.0 & 56.0 & 79.0 & 21.0 & 35.0 \\
\hline East central & 37.1 & 63.9 & 70.3 & 29.7 & 33.2 \\
\hline Eastern & 45.6 & 44.4 & 78.9 & 21.1 & 33.3 \\
\hline North & 59.3 & 40.7 & 88.6 & 11.4 & 29.3 \\
\hline Karamoja & 41.4 & 58.6 & 68.2 & 31.8 & 26.8 \\
\hline West-Nile & 44.2 & 55.8 & 74.2 & 25.8 & 30.0 \\
\hline Western & 48.2 & 51.8 & 79.3 & 20.7 & 31.1 \\
\hline Southwest & 36.9 & 64.1 & 79.3 & 20.7 & 42.4 \\
\hline Religion & $P=0.845$ & $x=1.394$ & $P=0.021$ & $x=11.587$ & \\
\hline Catholic & 49.8 & 50.2 & 79.5 & 20.5 & 29.7 \\
\hline Protestant & 41.8 & 58.2 & 78.4 & 21.6 & 36.6 \\
\hline Muslim & 46.1 & 53.9 & 79.2 & 20.8 & \\
\hline Pentecostal & 41.7 & 58.3 & 80.4 & 19.6 & 38.7 \\
\hline Other & 38.5 & 61.5 & 83.0 & 17.0 & 44.5 \\
\hline Wealth index & $P=0.137$ & $x=6.980$ & $P=0.000$ & $x=145.165$ & \\
\hline Poorest & 48.5 & 51.5 & 76.5 & 23.5 & 28.0 \\
\hline Poorer & 42.8 & 57.2 & 75.5 & 24.5 & 32.7 \\
\hline Middle & 44.3 & 55.3 & 76.1 & 23.9 & 31.8 \\
\hline Richer & 40.9 & 51.1 & 79.1 & 20.9 & 38.2 \\
\hline Richest & 50.3 & 49.7 & 86.7 & 13.3 & 36.4 \\
\hline Marital status & $P=0.000$ & $x=220.149$ & $P=0.134$ & 4.020 & \\
\hline Never in union & 36.3 & 63.7 & 75.1 & 24.9 & 38.8 \\
\hline Married & 75.6 & 24.4 & 80.2 & 19.8 & 4.6 \\
\hline Widowed & 84.1 & 15.9 & 77.6 & 22.4 & -6.5 \\
\hline Ever given birth & $P=0.000$ & $x=249.607$ & $P=0.000$ & $x=21.377$ & \\
\hline No & 37.4 & 62.6 & 70.5 & 29.5 & 33.1 \\
\hline Yes & 82.0 & 18.0 & 80.1 & 19.9 & -1.9 \\
\hline Comprehensive knowledge & $P=0.000$ & $x=14.549$ & $P=0.000$ & $x=94.603$ & \\
\hline No & 43.3 & 56.7 & 76.2 & 23.8 & 32.9 \\
\hline Yes & 49.4 & 50.6 & 84.4 & 15.6 & 35.0 \\
\hline Ever had sex & $P=0.000$ & $x=329.890$ & $P=0.000$ & 55.528 & \\
\hline No & 27.1 & 72.9 & 54.0 & 46.0 & 26.9 \\
\hline Yes & 67.8 & 32.2 & 80.0 & 20.0 & 12.2 \\
\hline HIV stigmatizing attitude & $P=0.000$ & $x=41.355$ & $P=0.000$ & $x=53.300$ & \\
\hline Yes & 42.7 & 57.3 & 77.5 & 22.5 & 34.8 \\
\hline No & 57.3 & 42.7 & 85.5 & 14.5 & 28.2 \\
\hline
\end{tabular}

Assessment is based on weighted data 
Table 3 Summary of decomposition of HTR

\begin{tabular}{llll}
\hline Components & Coef. & p-value & Percent (\%) \\
\hline E & 0.1932 & 0.000 & 57.21 \\
C & 0.1449 & 0.000 & 42.79 \\
R & 0.3387 & 0.000 & 100
\end{tabular}

Overall decomposition results of HIV Testing and Receipt of results (HTR); $\mathrm{n}=8674$; variations are attributed to differences due to endowments $(\mathrm{E})$ and coefficients (C); $R$ is the total variation

had sex, comprehensive knowledge and HIV stigmatizing attitudes $(\mathrm{P}<0.05)$. The variation in these characteristics of women contribute about $-6.5 \%, 0.2 \%$, $-0.5,31.6 \%, 34.7 \%, 0.4 \%$ and $0.8 \%$ to the overall gap in HIV testing difference in adolescent and non-adolescent women respectively. The positive percentages in the results show the proportion in which the overall gap would reduce if the differences in the characteristics of women in the two groups were to disappear. On the other hand, the negative percentage shows the proportion to which the gap in HIV testing would increase if the differences in the characteristics of women in the two groups were to disappear. The overall gap in HIV testing and receipt of results would reduce by $31.6 \%$, $34.7 \%, 0.4 \%, 0.8 \%$ and $0.2 \%$ if adolescent and non-adolescent women had similar proportion of their population in groups who have; ever given birth, ever had sex, comprehensive knowledge on HIV, HIV stigmatizing attitudes and place of residence respectively.

On the other hand, variation in the effects of characteristics (coefficients) contributed about $42.8 \%$ to the overall difference in HIV testing between adolescent and non-adolescent women. Specifically, the differences were significantly attributed to variation in the effects of characteristics of women namely; education and marital status $(\mathrm{p}<0.05)$. The variation in the effects of characteristics (coefficients) of women contribute about $-68.6 \%$ and $-12.6 \%$, to the overall gap in HIV testing change in adolescent and non-adolescent women respectively. In particular, the overall gap in HIV testing between adolescent and non-adolescent women would increase by $68.6 \%$ and $12.6 \%$ in the absence of variation in the effects of women's education and marital status respectively on HIV testing. $57.2 \%$ of the gap in the rates can be attributed to differences in the constants of the models for adolescent and non-adolescent women. This suggest that the study variables may be unable to fully explain the gaps in HIV testing and receipt of results as some behavioral and cultural factors may be difficult to measure due to the nature of the data.

\section{Discussion}

This study analyzed data from 2011 UDHS to assess differences in HIV testing and receipt of results between adolescent and non-adolescent women in Uganda. The findings show that differences in HIV testing and receipt of result can be attributed to both variation in characteristics (endowments) and variation in effects of characteristics (coefficients). In particular, the compositional variation in adolescent and non-adolescent women are noted in characteristics namely ever had sex, ever given birth, comprehensive knowledge on HIV/AIDS, stigmatizing attitudes, level of education and place of residence. Variation in the effect of characteristics (coefficient) also contributed to the changes for example variation in level of education and marital status though in a negative direction significantly contributed to differences in HIV testing and receipt of results between adolescent and non-adolescent women in Uganda.

The characteristics that had major contribution to the overall gap in HIV testing and receipt of results between adolescent and non-adolescent women were ever had sex and ever given birth. Having had sex explains the largest portion of the overall gap in HTR between the two groups. This points out to the issue of variation in perception of risk to HIV/AIDS between adolescent and non-adolescent. Adolescent women tend to perceive themselves as not being at high risk due to few exposure to hero-sexual intercourse which causes most of them not seek HIV testing. However this perception put adolescent women even at high risk of acquiring HIV in future as they undermine other sources of infections such as Mother-to-Child Transmission and sharing of sharp instruments. Besides, HIV testing has been found to be beneficial in reduction of risky sexual behaviors such as non-condom use, multiple sexual partnering, crossgenerational sex, commercial sex and drug use among young persons. These benefits of HIV testing may be missed by adolescent women due to low HIV testing and receipt of results. A study conducted among young people in Nigeria reported that young people who have ever had sex were about 2 times more likely to go for HIV test than their counterpart who had never had sex [3]. This was still confirmed by a study conducted among young women in Tanzania which found that women who have ever had sex were 4.4 times more likely to test for HIV compared to those who have never had sex [8]. Besides, studies have indicated that HIV testing besides helping individuals to know their HIV statuses, serves to reduce unsafe behaviors [15]. This therefore point to the need to scale up HIV testing among adolescent women by increasing on awareness that focuses on clearing misconceptions about HIV among adolescent women. 
Table 4 Decomposition of HIV testing and receipt of results ("000")

\begin{tabular}{|c|c|c|c|c|c|c|}
\hline \multirow[t]{2}{*}{ Variables } & \multicolumn{3}{|c|}{ Due to difference in characteristics (E) } & \multicolumn{3}{|c|}{ Due to difference in coefficients (C) } \\
\hline & Coefficient & P-value & percent & Coefficient & P-value & percent \\
\hline \multicolumn{7}{|l|}{ Education } \\
\hline No education & 1.000 & & & 1.000 & & \\
\hline Primary & -8.394 & 0.000 & -2.48 & -141.880 & 0.016 & -41.88 \\
\hline Post-primary & -13.733 & 0.000 & -4.05 & -90.469 & 0.005 & -26.70 \\
\hline \multicolumn{7}{|l|}{ Place of residence } \\
\hline Urban & 1.000 & & & 1.000 & & \\
\hline Rural & 0.568 & 0.003 & 0.17 & -49.461 & 0.302 & -14.60 \\
\hline \multicolumn{7}{|l|}{ Religion } \\
\hline Catholics & 1.000 & & & 1.000 & & \\
\hline Protestants & -0.184 & 0.335 & -0.05 & 9.818 & 0.401 & 1.91 \\
\hline Muslim & 0.010 & 0.934 & 0.01 & 6.458 & 0.324 & 1.91 \\
\hline Pentecostal & -0.050 & 0.746 & -0.01 & 8.607 & 0.242 & 2.54 \\
\hline Others & 0.001 & 0.405 & 0.00 & 3.270 & 0.284 & 0.97 \\
\hline \multicolumn{7}{|l|}{ Region } \\
\hline Kampala & 1.000 & & & 1.000 & & \\
\hline Central 1 & -0.182 & 0.104 & -0.05 & -0.759 & 0.939 & -0.22 \\
\hline Central 2 & 0.335 & 0.371 & 0.10 & -3.096 & 0.700 & -0.91 \\
\hline East central & -0.089 & 0.298 & -0.03 & -1.924 & 0.811 & -0.57 \\
\hline Eastern & -0.089 & 0.072 & -0.26 & -1.158 & 0.927 & -0.34 \\
\hline North & -0.993 & 0.000 & -0.29 & -5.155 & 0.512 & -1.52 \\
\hline Karamoja & 0.050 & 0.614 & 0.01 & -6.021 & 0.078 & -1.78 \\
\hline West-Nile & -0.283 & 0.221 & -0.08 & -4.775 & 0.342 & -1.41 \\
\hline Western & 0.024 & 0.075 & 0.01 & -7.560 & 0.529 & -2.23 \\
\hline Southwest & 0.748 & 0.004 & 0.22 & 0.874 & 0.689 & 0.26 \\
\hline \multicolumn{7}{|l|}{ Wealth index } \\
\hline Poorest & 1.000 & & & 1.000 & & \\
\hline Poorer & -0.552 & 0.166 & -0.16 & 0.365 & 0.689 & 0.077 \\
\hline Middle & -0.233 & 0.232 & -0.07 & -0.650 & 0.527 & -1.92 \\
\hline Richer & 0.162 & 0.896 & 0.08 & 0.708 & 0.959 & 0.21 \\
\hline Richest & -0.001 & 0.168 & -0.07 & -3.204 & 0.868 & -0.95 \\
\hline \multicolumn{7}{|l|}{ Marital status } \\
\hline Never in union & 1.000 & & & 1.000 & & \\
\hline Married/living together & -4.819 & 0.822 & -1.4 & -33.948 & 0.008 & -10.02 \\
\hline Widowed/separated & -5.886 & 0.822 & -1.7 & -7.017 & 0.017 & -2.07 \\
\hline \multicolumn{7}{|l|}{ Ever given birth } \\
\hline Yes & 1.000 & & & 1.000 & & \\
\hline No & 106.900 & 0.000 & 31.55 & -1.574 & 0.153 & -4.65 \\
\hline \multicolumn{7}{|l|}{ Ever had sex } \\
\hline Yes & 1.000 & & & 1.000 & & \\
\hline No & 116.500 & 0.000 & 34.72 & -8.119 & 0.779 & -2.40 \\
\hline \multicolumn{7}{|c|}{ Have comprehensive knowledge } \\
\hline No & 1.000 & & & 1.000 & & \\
\hline Yes & 1.369 & 0.002 & 0.40 & 12.439 & 0.319 & 3.67 \\
\hline \multicolumn{7}{|l|}{ HIV stigmatizing attitudes } \\
\hline Yes & 1.000 & & & 1.000 & & \\
\hline No & 2.529 & 0.001 & 0.75 & 8.153 & 0.328 & -2.41 \\
\hline Constant & & & & 494.080 & 0.000 & 145.84 \\
\hline Total & 0.194 & 0.000 & 57.211 & 0.145 & 0.000 & 42.79 \\
\hline
\end{tabular}

Italic values signifies $p<0.05$ 
Related to the above, having given birth was also found to be contributing a large portion to the overall gap in HIV testing and receipt of results between adolescent and non-adolescent women. This can be justified by the fact that majority of non-adolescent women have ever given birth and it is mandatory for couples to test for HIV during antenatal care in Uganda following mass campaigns on Elimination of Mother-to-Child Transmission of HIV (EMTCT). Less than quarter of adolescent women has ever given birth hence reducing the chances of testing for HIV compared to non-adolescent women. This reveals to government and development partners to scale up interventions targeting adolescent women for example in-school HIV testing counseling and testing and other adolescent friendly services.

Change in HIV testing and receipt of results between adolescent and non-adolescent women was also attributed to place of residence indicating that gap in HIV testing would reduce by at least $0.2 \%$ if this variation is removed. This can partly be attributed to concentration of health facilities in urban centers. This findings is consistent with a study conducted among young women in Tanzania which found out that young women with urban residence were 0.5 times more likely to test and receive their HIV result compared to the rural counterparts [3]. This finding directs government and other development partners to strengthen health services in rural areas in order to reduce the gap in HIV testing between adolescent and non-adolescent women in Uganda. However, this finding was contrary to studies conducted in Zimbabwe which did not find any significant relationship between place of residence and HIV testing [14].

Variation in level of education was also found in this study to have contributed to the overall gap in HIV testing and receipt of results between adolescent and nonadolescent women which is consistent with findings from a study conducted in Nigeria which revealed that young people with at least a secondary education are about 1.6 times more likely to access HCT than their counterpart with primary education or no education at all [3]. This finding was also confirmed from a study conducted in Tanzania which found that young women with secondary level of education were 5.5 times more likely to test and received their HIV result compared to those with no education [8].

\section{Conclusion}

The findings of this study provide evidences about differences in HIV testing and receipt of results between adolescent and non-adolescent women. Government and development partners should scale up interventions aimed at increasing uptake of HIV testing among adolescents. Such interventions may include increasing community outreach services and establishment of adolescent friendly HIV testing and counseling centers.

\section{Abbreviations}

AIDS: acquired immune-deficiency syndrome; ART: anti-retroviral therapy; HCT: HIV Counseling and Testing; HIV: human immune virus; HTR: HIV testing and receipt of results; $\mathrm{MoH}$ : Ministry of Health; PMTCT: prevention of mother to child transmission; UBOS: Uganda Bureau of Statistics; UDHS: Uganda Demographic Health Survey; UNAIDS: Joint United Nation Program on HIV/ AIDS; UNFPA: United Nation Fund for Population Activities; VCT: voluntary counseling and testing; WHO: World Health Organization.

\section{Acknowledgements}

The authors would like to appreciate Measure DHS for granting the permission to use 2011 UDHS data. Authors also acknowledge and appreciate German Academic Exchange Service (DAAD) for financial support to the first author. The contents of this paper represent the views of the authors and not supporting organization.

\section{Authors' contributions}

Conception and design of the study: SE, RW, BK. Acquisition of data: SE. Analysis and interpretation of data: SE, RW, BK. Drafting manuscript: SE, RW, BK. All authors read and approved the final manuscript.

\section{Funding}

The authors have no funding to report

\section{Ethics approval and consent to participate}

Ethical approval for study was not required because the data was secondary and available the in public domain. Permission to download and analyze UDHS was granted by Measure DHS program/ICF International.

\section{Consent for publication}

Not applicable.

\section{Competing interests}

The authors declare that they have no competing interests.

\section{Author details}

1 Department of Population Studies, School of Statistics and Planning, Makerere University, P.O BOX 7062, Kampala, Uganda. ${ }^{2}$ Department of Sociology and Social Administration, Kyambogo University, P.O BOX 1, Kyambogo, Kampala, Uganda. ${ }^{3}$ School of Statistics and Planning, Makerere University, P.O BOX 7062, Kampala, Uganda.

Received: 8 March 2018 Accepted: 30 July 2019

Published online: 12 August 2019

\section{References}

1. Ayiga N, Nambooze H, Nalugo S, Kaye D, Katamba A. The impact of HIV/ AIDS stigma on HIV counseling and testing in a high HIV prevalence population in Uganda. Afr Health Sci. 2013;13(2):278-86. https://doi. org/10.4314/ahs.v13i2.12.

2. Fanta W, Worku A. Determinants for refusal of HIV testing among women attending for antenatal care in Gambella. Reprod Health. 2012;9(8):1-13.

3. Ibrahim M, Ipadeola O, Adebayo S, Fatusi A. Socio-demographic determinants of HIV counseling and testing uptake among young people in Nigeria. Int J Prev Treat. 2013;2(3):23-31. https://doi.org/10.5923/j. ijpt.20130203.01.

4. Joint United Nations Programme on HIV/AIDS. (2011). 2011 United Nations General Assembly Political Declaration on HIV/AIDS: Targets and elimination commitments: ten targets: achive universal access to HIV prevention, care and support by 2015.

5. Joint United Nations Programme on HIV/AIDS. Press Release on HIV/AIDS. 2014a. http://www.unaids.org/en/resources/campaigns/2014/2014g apreport/videofootage/. 
6. Joint United Nations Programme on HIV/AIDS. (2014b). UNAIDS The Gap Report. 2014b. http://www.unaids.org/en/sites/default/files/media_asset /UNAIDS_Gap_report_en.

7. Madhivanan P, Krupp K, Kulkarni V, Kulkarni S, Vaidya N, Shaheen R, Philpott S, Fisher C. HIV testing among pregnant women living with HIV in India: are private healthcare providers routinely violating women's human rights? BMC Int Health Hum Rights. 2014;14(1):7.

8. Mahande MJ, Habib RO, Rune PN. Factors Associated with changes in HIV-testing uptake among young women (15-24 years) in Tanzania: analysis of 2003-2004, 2007-2008 and 2011-2012 Tanzania HIV/AIDS and Malaria Indicator Survey. Infect Dis Epidemiol. 2015;1(1):1-8.

9. Malaju MT, Alene GD. Assessment of utilization of provider-initiated HIV testing and counseling as an intervention for prevention of mother to child transmission of HIV and associated factors among pregnant women. BMC Public Health. 2012;12(226):1-8.

10. Mtenga SM, Exavery A, Kakoko D, Geubbels E. Social cognitive determinants of HIV voluntary counselling and testing uptake among married individuals in Dar es Salaam Tanzania: theory of Planned Behaviour (TPB). BMC Public Health. 2015. https://doi.org/10.1186/s12889-015-1545-4.

11. Ndzombane, L. An Investigation of the Uptake of Voluntary Counseling and Testing by Adolescents aged 15 to 19 at two Integrated Youth Friendly Service Sites in Gauteng, South Africa. 2012. 9,87,89,148.

12. Asante KO. HIV/AIDS knowledge and uptake of HIV counselling and test ing among undergraduate private university students in Accra, Ghana. Reprod Health. 2013;10(1):17. https://doi.org/10.1186/1742-4755-10-17.

13. Powers DA, Yoshioka H, Yun M-S. mvdemp: multivariate decomposition for nonlinear response models. Stata J. 2008:8:1.
14. Takarinda KC, Madyira LK, Mhangara M, Makaza V, Maphosa-Mutsaka M, Rusakaniko S, Kilmarx PH, Mutasa-Apollo T, Ncube G, Harries AD. Factors associated with ever being HIV-tested in Zimbabwe: an extended analysis of the Zimbabwe Demographic and Health Survey (2010-2011). PLoS ONE. 2016;11(1):e0147828. https://doi.org/10.1371/journal.pone.0147828.

15. Turner CF, Miller HG, Moses LE. Acquired immunodeficiency syndrome transmission: changes in knowledge and behaviors among teenagers, Massachusetts statewide surveys. Pediatrics. 1990;85:495.

16. UBOS and ICF International. Uganda Demographic and Health Survey 2011 Report, Vol. 7. Kampla; 2012.

17. Uganda Ministry of Health. HIV Counselling and Testing Policy. Kampala; 2010.

18. Uganda Ministry of Health \& ICF International. 2011 Uganda AIDS Indicator Survey.2012.

19. UNAIDS \& WHO. AIDS Epidemic Update 2007. Unaids, WHO. 2007. http:// data.unaids.org/pub/EPISlides/2007/2007_epiupdate_en.pdf.

20. UNICEF. Compendium of abstracts presented at the 17 th ICASA

21. Wusu O, Okoukoni S. The role of HIV counselling and testing in sexual health behaviour change among undergraduates in Lagos, Nigeria. Tanz J Health Res. 2011;13(1):27-32. https://doi.org/10.4314/thrb.v13i1.55672.

\section{Publisher's Note}

Springer Nature remains neutral with regard to jurisdictional claims in published maps and institutional affiliations.
Ready to submit your research? Choose BMC and benefit from:

- fast, convenient online submission

- thorough peer review by experienced researchers in your field

- rapid publication on acceptance

- support for research data, including large and complex data types

- gold Open Access which fosters wider collaboration and increased citations

- maximum visibility for your research: over $100 \mathrm{M}$ website views per year

At BMC, research is always in progress.

Learn more biomedcentral.com/submissions 